\title{
Design \& Simulation of Microstrip Patch Antenna for Uwb Applications
}

\author{
Chhavi Narayan Arora, R.L.Yadav
}

\begin{abstract}
Within the path of the closing multi decade, there may be a quick development being advanced of far off correspondence applications. The presentation of all such some distance flung frameworks is based totally upon the plan of the radio twine. Small scale strip radio wires are desired for more part of their programs and elements of interest. This paper shows the form and duplicate of spherical square restoration smaller scale strip reception equipment. the general reception equipment is planned and reenacted in microwave tool immoderate Frequency form Simulator (HFSS). The substrate utilized in this setup is FR4 and substrate is carried out with $\varepsilon_{-} r=4.4$. The proposed reception gadget is utilized for extraordinary far off correspondence applications. Addition, go back misfortune and information switch functionality are the exhibition parameter of proposed radio twine. The proposed recieving wire is broke down at thunderous recurrence of $4.4 \mathrm{GHz}$. the arrival misfortune is - $30.2 \mathrm{db}$ and increase of radio wire is eight.34. switch pace is superior as lots as one hundred sixty five.88\%
\end{abstract}

Keywords: Micro strip antenna, Miniaturized,Return Loss, Gain \& Bandwidth.

\section{INTRODUCTION}

In proper now, the progressed innovation of a long way off correspondence is increment step by step in step with the conditions. In consider to protection attitude, far flung interchanges are carried out in programmed affiliation and pals. a long way flung correspondence frameworks are applied to transmit images and recordings with better records charges, so small scale strip restore recieving wire is typically applied. Microstrip recuperation reception equipment turns out to be first rate grade by grade because of its simplicity of studies and creation, minimal attempt, mild weight, simple to inspire, functionality of double, triple and some recurrence duties and their attractive radiation attributes. As of overdue microstrip restoration radio wires have been extensively implemented in satellite interchanges, aviation, radars, biomedical programs and reflector sustains in light of its natural attributes, as an instance, exactly sturdy, similarity with coordinated circuits and fairly bendy as some distance as thunderous recurrence, polarization, example and impedance. no matter its few elements of hobby of microstrip reception system, they revel in the sick results of hazards, as an example, skinny statistics transmission, low gainetc. these

dangers restriction their programs in remarkable fields. so you can beat the constraints of microstrip repair recieving

Revised Version Manuscript Received on July 10, 2019.

Chhavi Narayan Arora, M.Tech Scholar, Department of Electronics and Communication Engineering, Galgotias College of Engineering \& Technology, Greater Noida, India.

Dr.R.L.Yadav, Professor, Department of Electronics and Communication Engineering, Galgotias College of Engineering \& Technology, Greater Noida, India. wires, various techniques are proposed for instance increasing the thickness of the dielectric substrate, diminishing dielectric consistent and making use of diverse states of restore. there are various states of repair like roundabout, square, triangular but roundabout and square are commonly mainstream. As of past due there has been exquisite exertion in the radio twine software to stifle the surface wave and beat the regulations of the antenna.the incentive within the again of this paper is to endorse a microstrip recieving wire a good way to boom the information transfer functionality with out increasing its bodily measurements [1]-[3].however, in sure programs the little size ordinary repair reception equipment is still excessively massive, so research is as but being centered across the cutting down of the restore reception apparatus in some unspecified time in the future of the years. on this paper, restore radio twine structure with minimum duration is one noteworthy idea. In our examinations the recovery affected the traits of the proposed reception equipment, as an instance, thunderous recurrence, transmission capability and radiation attributes, and so on.

The remainder of paper is configuration as pursues. The presentation of microstrip radio twine is depicted in segment I. The setup and structure of the proposed reception device and the parameters specifically for substrate and fasten are depicted in section 2 . In section three, the very last outcomes and discourse of proposed recieving twine contrasted and the conventional reception apparatus are defined.Finely the surrender is portrayed in vicinity four.

\section{RECIEVING TWINE CONFIGURATION AND LAYOUT}

On this phase, the form and research of the proposed radio wire as appeared in determine 1 is pointed out. recovery recieving twine is mimicked by using high Frequency Simulation shape (HFSS) programming.

\subsection{Circular square Patch Antenna layout}

A roundabout square repair reception apparatus is based and recreated here. The endorse system of research art work is advanced plan of radio wire with appropriate feed. In proposed recieving wire coaxial feed machine is carried out.

The right off the bat we plan the substrate having measurement forty $\times 50 \times$ zero. $8 \mathrm{~mm}$. The substrate has fabric Roger RT/Duroid and substrates is implemented with $\varepsilon \_r=2.33$ with zero.eight

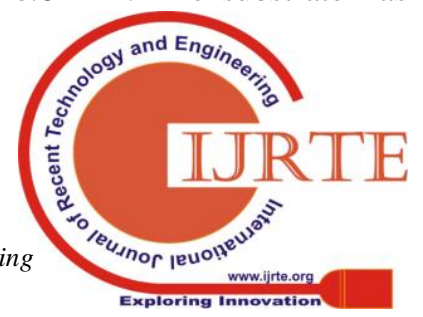


mm thickness.After making plans the substrates, at the top facet of the substrate, a radiatingpatch is outlined with nourishing focuses (zero,- five,zero). The element of round healing is $17 \mathrm{~mm}$ and length of rectangular repair is 12 .four $x$ sixteen.fifty nine $\mathrm{mm}$. The floor plane is positioned complete size on the opposite side of the substrate. The essential purpose of the overall paintings is to upgrade the transmission capacity and decline the arrival misfortune.

The proposed recieving twine is planned and mimicked in high Frequency Simulation shape (HFSS) programming. The restoration is worked at numerous frequencies of sixteen.6 $\mathrm{GHz}$ and $18.3 \mathrm{GHz}$ respectively. The essential schematic of recieving wire layout is regarded inside the figure 1.

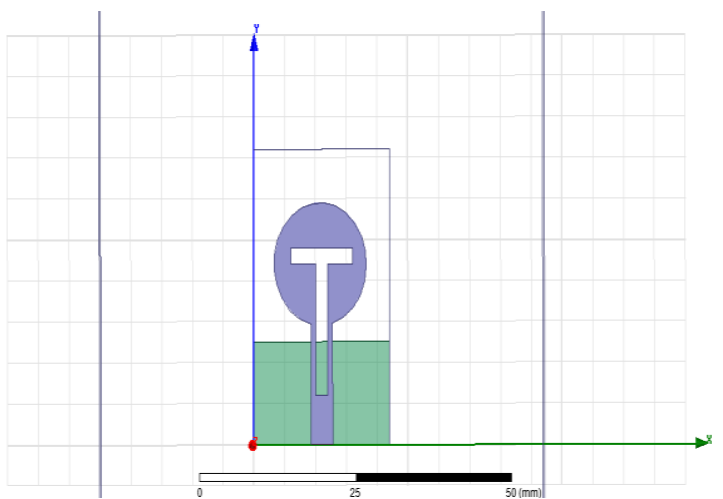

Figure 1:Top and Side View of the Proposed Antenna

The performance parameters of antenna is to be improve are gain, directivity, bandwidth and return loss. These parameter are as [21]:

\section{Directivity}

Directivity is the ratio of the radiation intensity in a given direction from the antenna to the radiation intensity averaged over all directions.

$$
\mathrm{D}=\frac{4 \pi U}{P_{\text {rad }}}
$$

\section{Gain}

Gain of an antenna is the ratio of the intensity, in a given direction, to the radiation intensity that would be obtained if the power accepted by the antenna were radiated isotropically.

$$
\text { Gain }=4 \pi \frac{\text { RadiationIntensity }}{\text { Totalinput (accepted }) \text { Power }}
$$

\section{Bandwidth}

The bandwidth of an antenna is defined as the range of frequency within the performance of the antenna. The bandwidth of narrow band and broadband antennas are defined as

$$
\text { B.W }=F_{h}-F_{l}
$$

\section{Return loss}

Return loss or reflection loss is the reflection of signal power from the insertion of a device in a transmission line. It is expressed as ratio in $\mathrm{dB}$ relative to the transmitted signal power. The return loss is given by

$$
\mathrm{RL}=10 \log \frac{P_{r}}{P_{i}}
$$

\section{RESULTS AND EXCHANGE}

Presently a days it is a typical exercise to assess the machine exhibitions through $\mathrm{PC}$ reproduction sooner than the ongoing execution. A test system "Ansoft HFSS" in view of on limited detail technique has been utilized to figure return misfortune, data transmission, and benefits. This test system also permits to diminish the manufacture expense as a result of reality best the radio wire with the fantastic fundamental by and large execution is most likely created [1]. figure 2 demonstrates the reenacted impacts of the return loss of the proposed recieving wire. After Simulation the go returned misfortune is gained - $35.7673 \mathrm{db}$ with bit of leeway five. $6925 \mathrm{db}$ and data transfer capacity $563 \mathrm{MHz}$ at $16.6 \mathrm{GHz}$. Recurrence Vs return Loss is demonstrated in fig 2. An awful rate for cross again misfortune demonstrates that this reception apparatus had relatively few misfortunes while transmitting the signs. Reception apparatus is some extraordinary one worked at $18.3 \mathrm{GHz}$. After recreation return misfortune is gotten $-29.2070 \mathrm{db}$ with bit of leeway 12.forty four $\mathrm{db}$ and transfer speed $268 \mathrm{MHz}$ at $18.3 \mathrm{GHz}$. Recurrence Vs return Loss is appeared in fig 2.
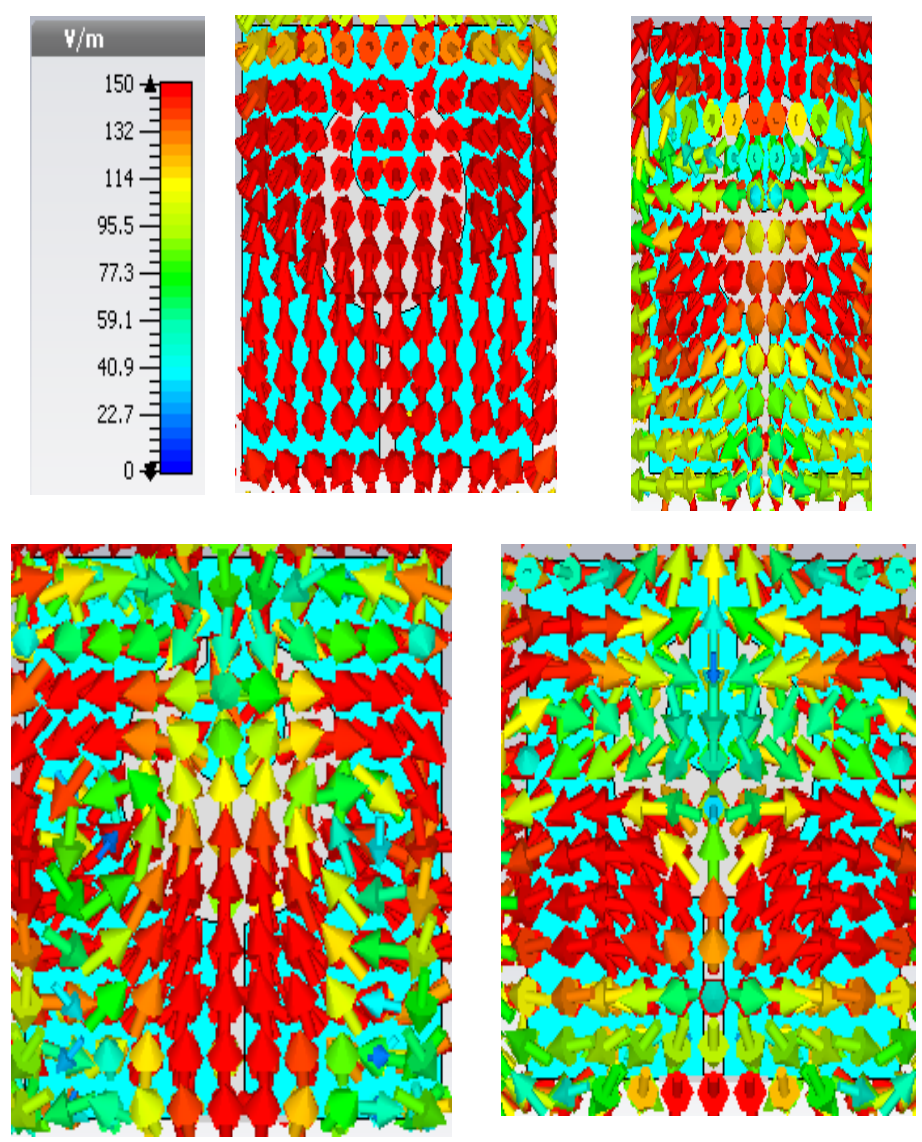


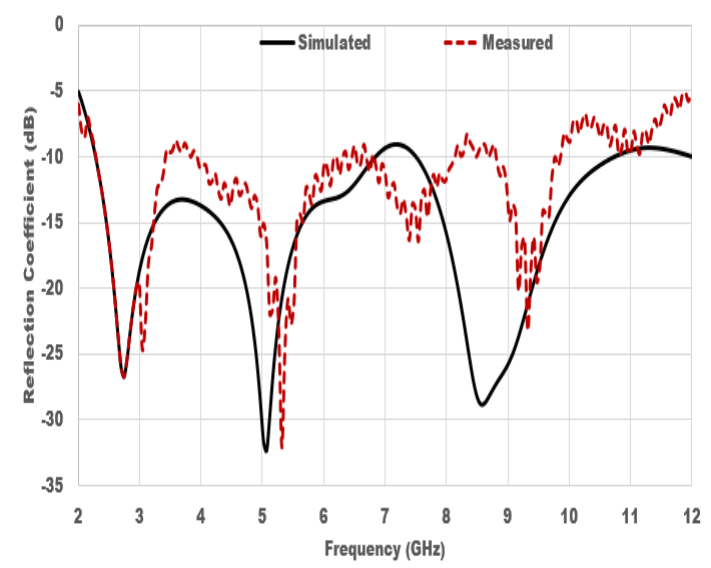

Fig 2 Comparative Analysis of Simulated \& Measured Return loss

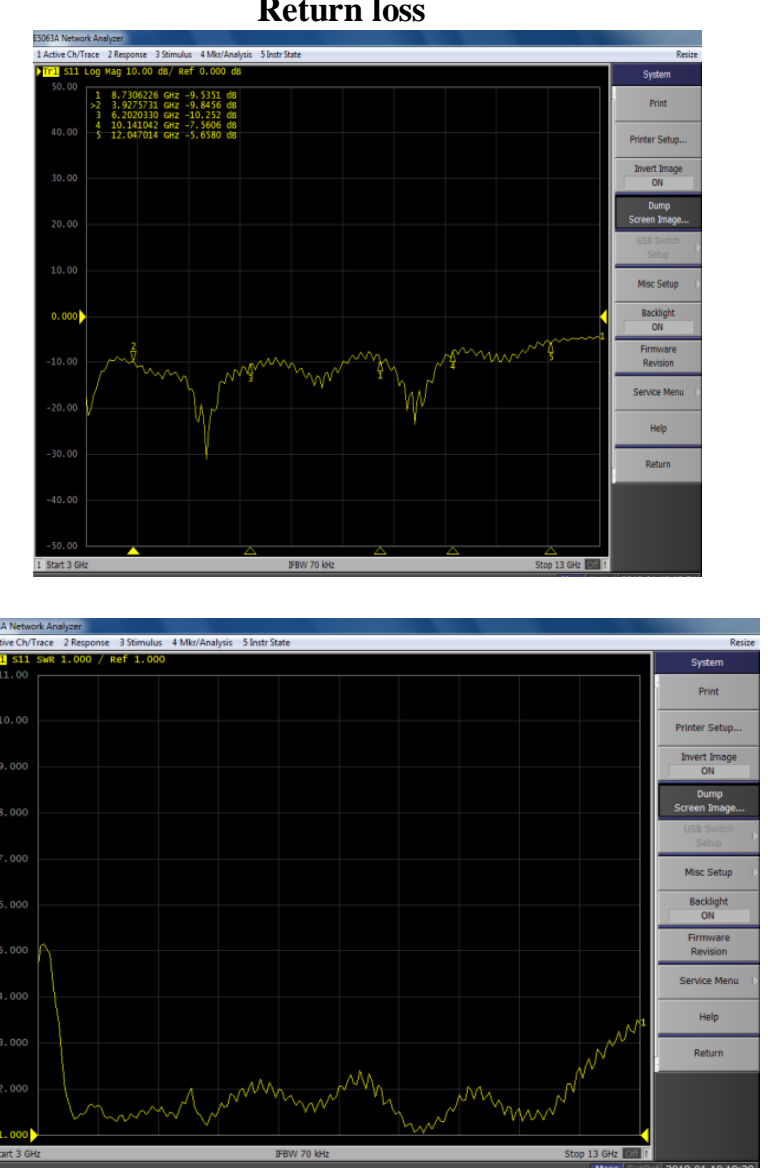

Fig 3 3-D Gain Plot

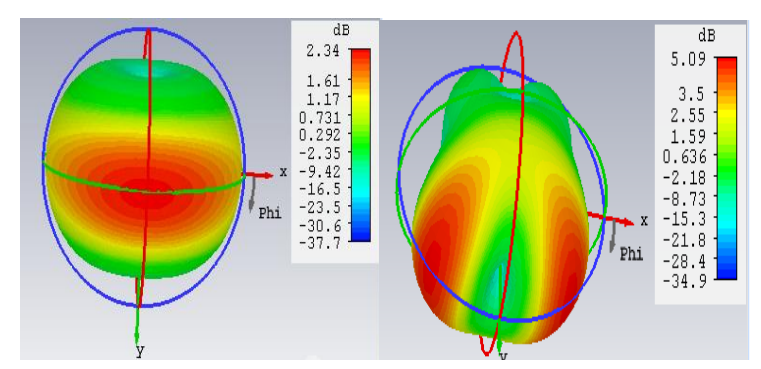

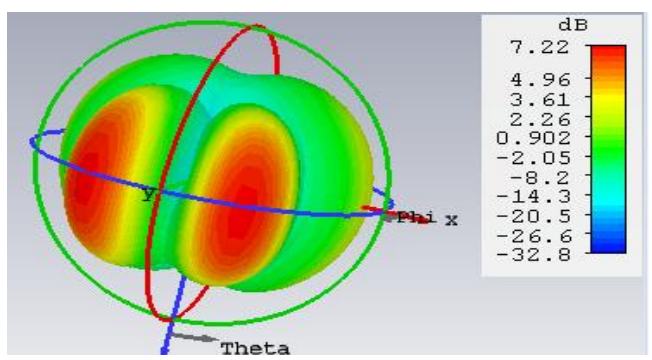

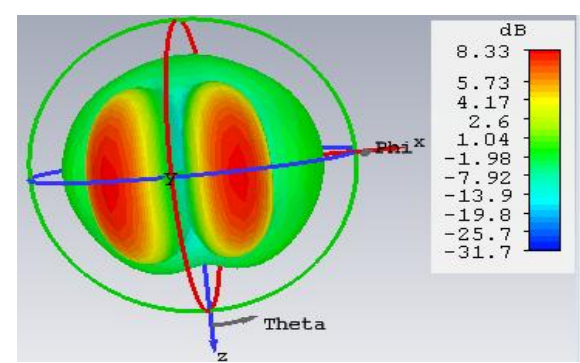

Fig 4 Gain at frequency of $2.5,5.5,8.5$, and $9.5 \mathrm{GHz}$, Maximum gain reported 8.33

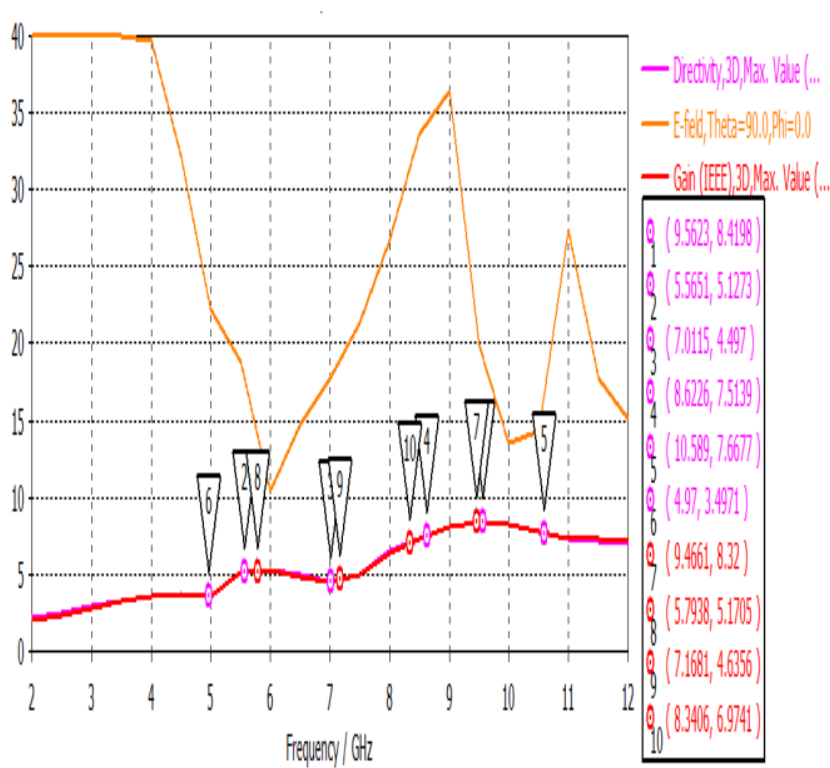

Fig 5Gainvs directivity and axial ratio

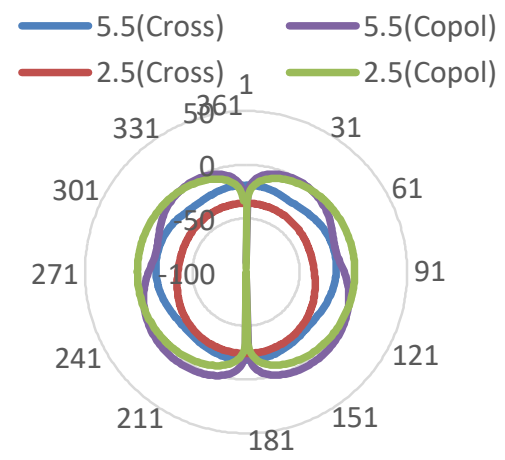

(a)

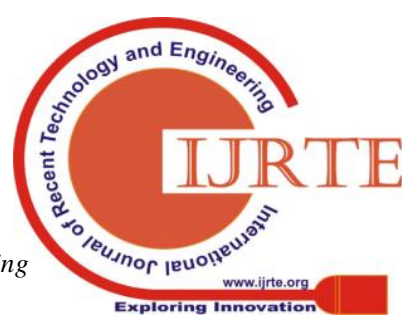



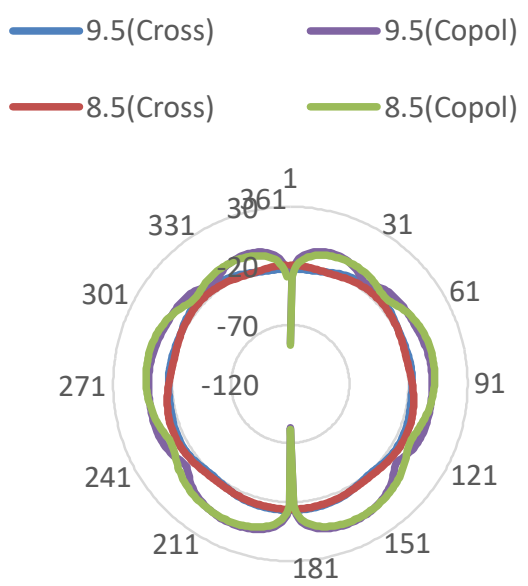

(b)

Fig 6 Co and Cross polarization of shaped antenna

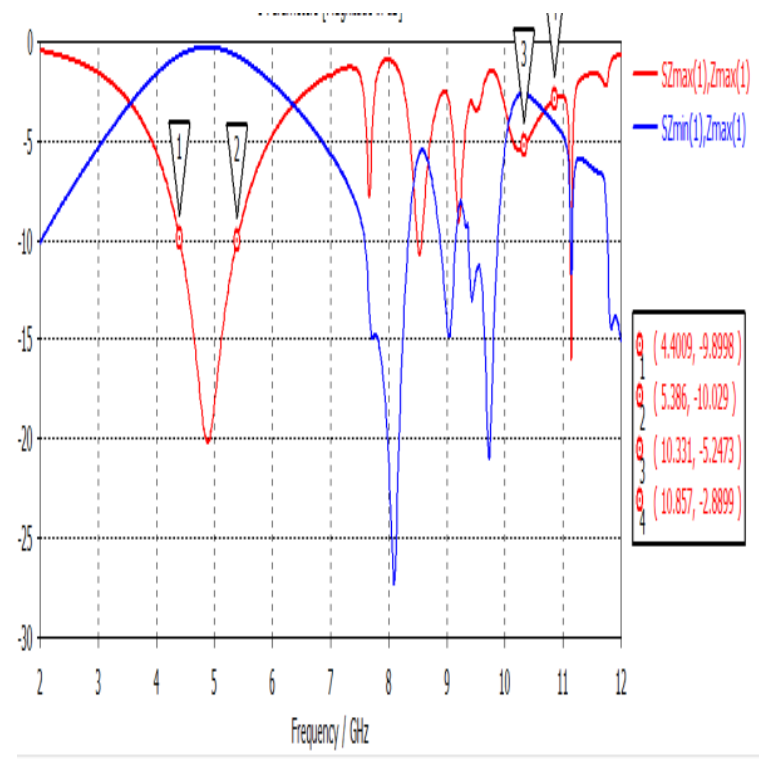

Fig 7 Impedance Curve of Antenna

Table 1 Comparison table of UWB for different shapes of patch

\begin{tabular}{|c|c|c|c|c|}
\hline Authors & $\begin{array}{l}\text { Frequency } \\
\text { band }\end{array}$ & Feed line Type & $\operatorname{Gain}(\mathrm{dB})$ & Size $(\mathrm{mm})$ \\
\hline $\begin{array}{l}\text { Priyanka Das } \\
\text { et al. [l] }\end{array}$ & 4.7 to $14.9 \mathrm{GHz}$ & Microstripfeadline & $\begin{array}{l}9.2 \mathrm{dBi} \text { with metamaterial } \\
5 \mathrm{dBi} \text { without metamaterial }\end{array}$ & $27 \times 20$ \\
\hline $\begin{array}{l}\text { Ming- } \\
\text { ChunTunget } \\
\text { a. [2] }\end{array}$ & $\begin{array}{l}2.99 \text { to } 11.07 \\
\mathrm{GHz}\end{array}$ & Microstripfeedline & $6 \mathrm{~dB}$ at $10 \mathrm{GHz}$ & $37 \times 25$ \\
\hline $\begin{array}{l}\text { DeapaNegi at } \\
\text { a. [3] }\end{array}$ & 6 to $10.2 \mathrm{GHz}$ & Microstripfeedline & $\begin{array}{l}7.2 \mathrm{~dB} \text { with metamaterial } \\
4.7 \mathrm{~dB} \text { without metamaterial }\end{array}$ & $50 \times 43$ \\
\hline $\begin{array}{l}\text { Huy H. Tran et } \\
\text { a. [4] }\end{array}$ & 3.2 to $8.8 \mathrm{GHz}$ & Coaxial Fed & $\begin{array}{l}11.1 \mathrm{dBi} \text { (Using parasitic } \\
\text { elements) }\end{array}$ & $50 \times 65$ \\
\hline $\begin{array}{l}\text { DeapaNegi at } \\
\text { a. [5] }\end{array}$ & 3.1 to $10.6 \mathrm{GHz}$ & Microstripfeedline & $6.1 \mathrm{Db}$ & $30 \times 30$ \\
\hline $\begin{array}{l}\text { Proposed } \\
\text { Antenna }\end{array}$ & $\begin{array}{l}2.27 \text { to } 10.73 \\
\mathrm{GHz}\end{array}$ & microstripfeadline & $\begin{array}{l}8.34 \mathrm{~dB} \text { without any } \\
\text { enhancement techniques }\end{array}$ & $48 \times 50$ \\
\hline
\end{tabular}

\section{CONCLUSION}

The structure and pastime of severa united states of miniaturized scale strip reception equipment has been pondered the usage of HFSS programming. The endeavor work gives first-rate very last consequences thru fix mini-computer. here proper fixing with the aid of resounding recurrence has been completed. The exam has been completely completed throughout activity artwork.extremely massive band repair radio wires have immoderate increase and fine thunderous recurrence for example $5.1 \mathrm{GHz}$ even as contrasted with exceptional states of microstrip restore antennas.Proposed Fabricated microstrip repair reception apparatuses have least move again misfortune i.e - $30.2 \mathrm{db}$ at its resounding recurrence five. $1 \mathrm{GHz}$. Addition is likewise a issue advanced by way of using proposed reproduced recieving twine and it received as to $8.34 \mathrm{db}$. Transmission capacity of proposed radio wire is also superior as a good deal as one hundred sixty five. $88 \%$

\section{REFERENCES}

1. Das, Priyanka, and KaushikMandal. "displaying of extremely-giant prevent-band recurrence specific ground to upgrade the boom of a UWB radio wire." IET Microwaves, Antennas and Propagation13.3 (2018): 269-277.

2. Tang, Ming-Chun, Ting Shi, and Richard W. Ziolkowski "Planar ultrawideband radio wires with improved acknowledged increase execution." IEEE Transactions on Antennas and Propagation sixty 4.1 (2015): sixty one-69.

3. Negi, Deepa, Rajesh Khanna, and JaswinderKaur. "shape and execution studies of a conformal CPW nourished wideband radio twine with $\mathrm{Mu}$-negative metamaterial for wearable applications." international magazine of Microwave and wi-fi generation: 1-15.

4. Tran, Huy H., and Tuan T. Le. "high-gain twin-polarized radio wire for ultrawideband programs." international mag of RF and Microwave laptop-Aided Engineering 29.eight (2019): e21782.

5. Negi, Deepa, Rajesh Khanna, and JaswinderKaur "Multi-Resonating structures for Broadband Impedance Matching in Ultrawideband Antenna." wi-fi private Communications(2019): 1-21

6. Jagtar Singh, A.P Singh, T.S. Kamal, "on the design of Triangular Microstrip Antenna for wireless conversation", worldwide magazine of laptop applications-IJCA, Feb 2012.

7. Kumar Ashok, Singh Pushpendra, D.Sunita, "research and programs of Microstrip Antennas Having Magnetic materials",1st international conference on upgrades and advancements in statistics and communique technology-ICIAICT 2012.

8. AhmetCemalDurgun et.al "structure, Simulation, Fabrication and trying out of flexible Bow-Tie Antennas" IEEE Transactions on Antennas and Propagation, Vol. fifty nine, No. 12, December 201

9. David M. Pozar, Microwave Engineering second launch, John Wiley and Son, Inc.1998. 
10. Verma M.adequate., Verma S, Dhubkarya, D.C, "studies and structuring of E-shape microstrip healing radio wire for the faraway correspondence frameworks," rising developments in virtual and Photonic gadgets and systems, 2009. ELECTRO' 09. global convention on wireless Comm., vol., no., pp.324-327, 22-24 Dec. 2009

11. C. Chiu and R. D. Murch, "Conservative four-port reception equipment appropriate for versatile UWB devices," IEEE Antenna wireless Propag.Lett., vol. 7, pp. 142-one hundred forty four, 2008.

12. X. Zhou, X. Quan, and R. Li, "A double broadband UWB reception system framework for GSM/UMTS/LTE and WLAN handsets," IEEE AntennaWirelessPropag.Lett., vol. 11, pp. 551-554, 2012.

13. S. Karimkashi, A. A. Kishk, and D. Kajfez, "Reception device display off development utilising dipole fashions for UWB programs," IEEE Trans. AntennaPropag., vol. 59, no. 8, pp. 3112-3116, 2011.

14. S. Zang, P. Zetterberg, and S.He, "posted UWB reception system affiliation of four firmly separated additives with big information switch ability and excessive seclusion," Electron.Lett., vol. 46, no. 15, pp. 1052-1053, 2010.

15. H. Zhang, Z. Wang, J. Yu, and J. Huang, "A conservative UWB recieving cord for a ways flung correspondence," IEEE Antenna Propag.magazine., vol. 50, no. 6, pp. 104-107, 2008.

16. Jain, P. ok. Verma, and V. okay. Singh, "Execution studies of PFIA primarily based 4 UWB recieving wire," Electron. Lett., vol. forty eight, no. nine, pp. 474-475, 2012.

17. M. S. Sharawi, M. A. Jan, and D. N. Aloi, "four-fashioned 2 multi-famous minimized exclusive inputmultiple-yield radio twine framework for long haul development portable handsets," IET Microw. AntennasPropag., vol. 6, no. 6, pp. 685-696, 2012.

18. adequate. Z. Rajab, R. Mittra, and M. T. Lanagan, "duration lower of microstrip restoration recieving wires with left-gave transmission line stacking," IET Microw. Reception apparatuses Propag., vol. 1, no. 1, pp. 39-forty 4, 2007.

19. L. Desclos, Y. Mahe, S. Reed, G. Poilasne, and S. Toutain, "repair reception apparatus length lower via consolidating inductive stacking and short-focuses tool," Microw. choose out. Technol. Lett., vol. 30, no. 6, pp. 385-386, 2001.

20. X. Cheng, D. E. Senior, C. Kim, and Y.- ok.Yoon, "A conservative omnidirectional self-bundled restoration recieving twine with reciprocal break up ring resonator stacking for a long way flung endoscope packages," IEEE Antenna wi-fi Propag.Lett., vol. 10, pp. 1532-1535, 2011.

21. Y. Dong, H. Toyao, and T. Itoh, "Plan and portrayal of scaled down repair reception equipment stacked with necessary break up-ring resonators," IEEE Trans. Reception gadget Propag., vol. 60, no. 2, pp. 772-785, 2012. 